\title{
Evaluating process-based and crew- centred approaches to procedure design in aviation: workload and performance changes in go-around manoeuvres.
}

\author{
Tim André Schmidt, Houda Kerkoub Kourdali and Jim Nixon
}

\begin{abstract}
In this article, we compare and evaluate two methods of procedure design using an aircraft go-around (GA) as a test scenario. We contrast the manufacturer specified, crew-centric procedure with a redesigned process-centred perspective. We test the claim that the process-centred design can take into account situational factors more effectively and generate less workload. We report a heuristic assessment of the new procedure against design guidelines and an evaluation in a full-flight simulator at the German Aerospace Centre (DLR) using qualified airline pilots to assess workload and performance. Both the manufacturer specified and new procedure were employed in three GA scenarios representative of increasing operational complexity. Results demonstrate an advantage for the new procedure design in the most complex scenario. The new, process-based procedure can reduce reported crew workload and improve response flexibility in more complex scenarios, improving rated performance. This study suggests that the process-based account in procedure design has advantages when compared to the flight crew-centric approach. These advantages include an enhanced flexibility, robustness and improved crew performance during GA.
\end{abstract}

Keywords: Standard Operating Procedures, Go-Around, Procedure design, Workload. 


\section{INTRODUCTION}

In this article, we evaluate two methods of procedure design using an aircraft go-around (GA) as a test scenario. We redesign a manufacturer specified procedure using the processcentred perspective. This perspective can take into account situation changes in dynamic flight operations more effectively. Our evaluation contributes to a new practical application of a process-centred procedural design demonstrating how this is achieved in the selected scenario. In addition, we report preliminary empirical evidence of the performance improvement that could be achieved using this alternative theoretical perspective on standard operating procedure (SOP) design.

SOPs provide the basis of conducting safe flight operations (Cahill et al., 2017). Procedures define the script for the wide-ranging interactions between aircrew (Degani et al., 1999), aircraft systems (Mauro et al., 2012) and the operational environment (Barshi et al., 2016). The workflows defined by SOPs should be appropriate for the operation (FAA, 2003) such that tasks are completed in a logical, intuitive sequence, avoiding any overlaps or disruption (Kourdali \& Sherry, 2016b). To be effective, SOPs should be clearly communicated by procedures and checklists (Drury, 1998; Patel et al. 1994).

In reality, this goal is at times not achieved. Indeed, problems with the use of procedures have not decreased over time (Drury et al., 2017a; 2017b) and continue to be represented in aircraft accidents and incidents (Drury \& Johnson, 2013). The human factors literature highlights that procedures can lack a clear operational logic (Degani \& Wiener, 1998), are poorly designed (Funk et al., 2009), inherently incorrect (Degani \& Wiener, 1997) or do not adequately address human limitations (Kemeny \& Popp, 2016). These issues can disrupt safe operation of the aircraft or create unanticipated work for the aircrew. Moreover, SOPs that are not practical to use can impose multiple task demands (Loukupoulos et al., 2003, 2009) leading flight crews to deviate from the procedures and to adapt the task sequence to the operational environment (de Terssac \& Chabaud, 1990; de Brito, 1998; BEA, 2013; Carim et al., 2016; Jones et al., 2018). Compliance with procedures remains an ongoing 
issue despite our increased understanding of their effective design and implementation (Drury et al. 2017a).

Cahill et al. (2014) identify two types of procedure design: crew and process-based centric design. Characteristics of both approaches are summarised in Table 1. The crew-centric design philosophy captures the linear workflows typically associated with procedure design; the process-based perspective captures the ways in which the flight crew actually apply procedures. In this research we extend the theoretical to a simulator evaluation of the two different procedure philosophies.

The crew-centric approach emphasises that cockpit operations do not always follow the workflow linearly, and therefore not all operational conditions can be considered in a written procedure while maintaining an appropriate length (Pelegrin, 2007; Cahill et al., 2014; Maille, 2016; Surabatualla et al., 2019). However, situation-dependent deviations from SOPs can vary from flight to flight and even from moment to moment (Loukupoulos et al., 2009). These deviations can interfere with the execution of habitual tasks which can impact on safety (Loukupoulos et al., 2009), particularly in dynamic or complex flight phases such as the GA. The process-based procedures can contextualise these deviations and may offer a way in which to bring work as imagined and work as done closer together (Cahill et al., 2014).

Table 1 Characteristics of crew-centric and process-based perspective in procedure design.

\begin{tabular}{ll}
\hline $\begin{array}{l}\text { Crew Centric Perspective on Task } \\
\text { Performance }\end{array}$ & $\begin{array}{l}\text { Process-Based Perspective on Task } \\
\text { Performance }\end{array}$ \\
\hline $\begin{array}{ll}\text { Local explanation. } \\
\text { Good performance is through application of } \\
\text { SOPs. }\end{array}$ & $\begin{array}{l}\text { Good performance can be inhibited by the } \\
\text { organization of procedural steps as written } \\
\text { down in SOPs. }\end{array}$ \\
\hline $\begin{array}{l}\text { Linear workflow structured through process- } \\
\text { gates that must be accomplished or the task } \\
\text { flow does not move forward. }\end{array}$ & $\begin{array}{l}\text { Non-linear workflow that varies according to the } \\
\text { level of operational and environmental } \\
\text { complexity. }\end{array}$ \\
\hline
\end{tabular}




\begin{tabular}{ll}
\hline $\begin{array}{l}\text { Focus on when and how information is shared at } \\
\text { pre-defined times in the process. }\end{array}$ & $\begin{array}{l}\text { Focus on collaborative requirements at pre- } \\
\text { defined times in the process. }\end{array}$ \\
\hline $\begin{array}{ll}\text { SOP design can be difficult to follow due to a } \\
\text { narrow picture of task operation which fails to }\end{array}$ & $\begin{array}{l}\text { SOP design represents the normal practice of } \\
\text { how flight crews apply procedures and expertise } \\
\begin{array}{l}\text { capture the management of operational and } \\
\text { environmental complexity. }\end{array}\end{array}$ \\
\hline
\end{tabular}

In this article, we focus on the GA procedure as a candidate with which to test the two different approaches to design. The GA is a normal flight manoeuvre conducted by flight crews if a landing cannot be completed (Manchanda \& Sikora, 2016). This may be for a number of reasons including obstruction on a runway or an unstable approach necessitating reconfiguration of the aircraft. For most commercial pilots the GA is not a common event (Blajev \& Curtis, 2017). Across the worldwide Airbus A320 fleet, the GA rate equals to 0.29 percent which corresponds to one GA for every 340 approaches (Marconnet \& Roland, 2014). Regular training and compliance to SOPs ensure that the GA procedure flows well when performed correctly (ATSB, 2014). Nonetheless, characterising the GA as a normal and scripted flight phase does not exclude risk (GA Safety Forum, 2013). High workload and the different circumstances under which a GA can arise (Airbus, 2017a) may lead to a loss of state awareness (BEA, 2013). Several GA accident and incidents support this conclusion (for example Kingdom of Bahrain CAA, 2000; ATSB, 2007, 2014; BEA, 2000, 2007, 2009; JTSB, 2016).

Investigative findings from these incidents and accidents point to variable performance of SOP implementation and shortcomings in crew resource management (CRM) (BEA, 2013) which can impact on safety (Dehais et al., 2017). Cahill et al. (2014) argue that these deficiencies are partially caused by the design of rigid crew function allocations that are based on a flight crew-centric perspective on task activities. This perspective assumes that information within the flight crew and external agents like air traffic control are shared at predefined times (Cahill et al. 2014). During the GA, this perspective is perhaps justified because the flight crew acts across different operational roles and their activities are directly 
related to changes of the aircraft states that may occur at predefined times depending on aircraft performance (Cahill et al., 2014). However, the crew-centric perspective is solely based on the physical configuration of multi-crew cockpits (Kemeny \& Popp, 2016) that may not reflect the operational complexity of the GA. This complexity arises since pilots are sometimes unable to execute the procedural steps, either because the situation requires handling unexpected tasks so that procedural steps are interleaved or because the action by one pilot cannot be performed because the necessary trigger is not yet available (Loukupoulos et al., 2003, 2009). The necessary trigger during the GA can be a callout such as 'Positive Climb'. The pilot monitoring (PM) must perform the callout before the pilot flying (PF) requests 'Gear Up', otherwise, the task sequence is interrupted which may cause risk.

During a GA, the problem of interleaving or deferment tasks is acute for the operational role of the pilot monitoring (PM). On the flight deck the PM performs multiple roles monitoring system related states and performing tasks on command by the PF, all while communicating with air traffic control. Recent GA studies (BEA, 2013; Dehais et al., 2017; Blajev \& Curtis, 2017) suggest that safety-critical tasks like flight path monitoring and mode awareness are vulnerable to error. We suggest that the procedure design contributes to this vulnerability because the task sharing does not account for the complex operation (Cahill et al., 2014). Instead, the numerous tasks during GA can leave the PM ill-equipped to handle the sudden onset of additional task demands while concurrently monitoring the flight path (Dehais et al., 2017).

A broader process-based account in procedure design may improve this situation by taking a holistic view on flight crew activities and it is this hypothesis that we test in this article. The process-based approach takes into account the team dimension of flight crew tasks that are linked to the wider operational process and associated information flow requirements. Following this approach, the procedure design mirrors the operational process in which the flight crew manages the flight involving different levels of operational complexity (Cahill et al., 2014). 
In this study, we develop a new process-based procedure for the GA. We compare performance of this design with the manufacturer-specified crew-centric procedure. We measure workload of pilots performing the GA procedures under different contexts and present a heuristic evaluation of the new procedure design. The research addresses two aims:

1) To evaluate and compare a crew-centric procedure and develop a process-based procedure.

2) To assess differences in performance and workload associated with the two different procedural designs.

To address the aims of the study the new GA procedure was developed and tested using a heuristic evaluation and through a high-fidelity simulation using three different scenarios. We first present the development of the new procedure then the evaluative components of the work.

\section{Crew-centric and process-based go-around procedure}

\subsection{Development of new process-centred procedure}

To meet the study aims, two GA procedures were compared. The manufacturer crew-centric procedure and the new, process-based procedure (refer to Figure 1).

We developed the new procedure starting with multi-scenario based modelling of the GA. Multi-scenario based modelling considers different levels of complexity in the selected operation. The objective of this modelling activity is to define an ideal cockpit operation. This is then followed by creation and identification of a range of different scenarios that may place higher demands on the crew. In this article we consider three different GA scenarios.

Firstly, we captured the ideal sequence of cockpit duties demanded by considering the manufacturer specified, crew-centred GA procedure. To achieve this, a review of the flight crew training manual (Airbus, 2017b) and the related flight guidance systems descriptions 
(ATG, 1999; Norden, 2010; Granger \& Jeanpierre, 2011; Marconnet \& Roland, 2014; Fernandez et al., 2017) was conducted.

Secondly, to identify different scenarios in which pilots may be more challenged, we reviewed both literature (Dehais et al., 2017; BEA, 2013) and accident/ incident reports associated with GA (for example Kingdom of Bahrain CAA, 2000; ATSB, 2007, 2014; BEA 2000, 2007, 2009; JTSB, 2016). Following this review we identified two additional scenarios with different operational complexity. These additional scenarios represent operations where there is pressure on the appropriate completion of the crew-centred procedure and increased risk for procedural non-compliance during the GA. As such, these scenarios are treated as candidates for the process-based modification.

For all three scenarios we then conducted hierarchical task analyses (HTA) using the Airbus extended HTA tool (xHTA) (Rabl et al., 2018). This tool supports the development of an HTA and offers the opportunity to visualise procedural sequences showing concurrent tasks and task-type. The HTA was validated using interviews with six airline pilots followed by full-flight simulator observations to compare behaviour against the task sequences. Using the $\mathrm{xHTA}$ visualisation functionality we were able to identify the sequence of interactions between flight crew members and the aircraft systems. Examples of the xHTA visualisations are shown in the electronic supplementary material and could just as well be achieved using an off-theshelf diagramming package.

Through consideration of the visualisations we identified triggers for different tasks, tasktiming and tempo, to understand how flight crews interact during the GA while performing the procedure in the different scenarios. Difficulties in the areas of crew coordination, workload management and rigidity in the procedure were identified as candidate task groups or procedural steps to apply the process centred philosophy. In addition, the difficulties identified were reported as problematic in the literature considered in the earlier review (Dehais et al., 2017; BEA, 2013) confirming suitability for further procedure development. 
To achieve the process-based procedure, we applied three design modifications: simplified aircraft configuration management, parallel workflows and adaptive task management. These key design goals were specified after the HTA review and are informed by the process-based philosophy that emphasises context and expertise. The specifics of the design decisions can be found in the electronic supplementary material. Informed by the process-based perspective, we developed design modifications to resolve the issues identified in the HTAs. This was done in conjunction with SMEs that included airline pilots. Finally, we re-visualised the new procedural sequences using $\mathrm{xHTA}$ to provide a direct comparison between the crew-centric and process-based procedure ready for the heuristic assessment. Each of the three key modifications are discussed in this section.

\section{Simplify configuration management}

The main challenge for the performance of a safe GA remains finding ways of giving the flight crew time to perform their actions (BEA, 2013). From a process-based perspective, this requires addressing the operational complexity through simplification of lower priority tasks. The process-based procedure captures this requirement by simplifying the aircraft configuration change management through a delay of the flap retraction to increase the PM's monitoring ability at GA initiation. In doing so, monitoring of the aircraft attitude and energy state at GA initiation becomes a primary task of the PM (see Figure 1) while in the manufacturer procedure it is a secondary task to be performed concurrently with the configuration change. 


\begin{tabular}{|c|c|c|c|}
\hline Manufacturer Go-Around Procedure & & Process-Based Go-Around Procedure & \\
\hline Go-Around Initiation Phase & & Go-Around Initiation Phase & \\
\hline Apply the following three actions simultaneously: & & Apply the following three actions simultaneously: & \\
\hline THRUST LEVERS & PF & THRUST LEVERS. & PF \\
\hline ROTATION.....PERFORM & $\mathrm{PF}$ & ROTATION. & PF \\
\hline GO AROUND - FLAPS & PF & GO AROUND & $\mathrm{PF}$ \\
\hline FLAPS LEVER & PM & A/C ATTITUDE \& ENERGY....................... & PM \\
\hline FMA & PF & FMA. ANNOUNCE & $\mathrm{PF}$ \\
\hline POSITIVE CLIMB & PF & POSITIVE CLIMB & PM \\
\hline L/G UP & PF & $\begin{array}{l}\text { Adaptive Task Management - } \\
\text { FLAPS LEVER }\end{array}$ & PM \\
\hline L/G LEVER UP & PM & L/G LEVER UP. & PM \\
\hline NAV or HDG MODE & PM & $\begin{array}{l}\text { Adaptive Task Management - } 2 \\
\text { NAV or HDG MODE.......................... RQRD } \\
\text { Note: Standard Sequence is ATM1 following ATM2. } \\
\text { PM decides if change between ATM1 and ATM2 is needed. }\end{array}$ & PM \\
\hline 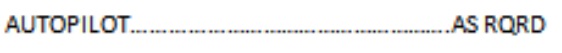 & $\mathrm{PF}$ & AUTOPILOT & $\mathrm{PF}$ \\
\hline AIR TRAFFIC CONTROL............................... & PM & AIR TRAFFIC CONTROL & PM \\
\hline Thrust Reduction Phase & & Thrust Reduction Phase & \\
\hline At Go-Around Thrust Reduction Altitude & & At Go-Around Thrust Reduction Altitude & \\
\hline THRUST LEVERS. & PF & THRUST LEVERS & $\mathrm{PF}$ \\
\hline Flap Retraction Phase & & Flap Retraction Phase & \\
\hline At Go-Around Acceleration Altitude: & & At Go-Around Acceleration Altitude & \\
\hline Monitor target speed increase to green dot. & & Monitor target speed increase to green dot. & \\
\hline At F-Speed: & & At F-Speed: & \\
\hline Flaps 1........ ORDER & $\mathrm{PF}$ & S........... & PM \\
\hline Flaps 1 . & PM & & \\
\hline Slat Retraction Phase & & Slat Retraction Phase & \\
\hline At S-Speed: & & At S-Speed: & PM \\
\hline $\begin{array}{l}\text { Flaps 0 } \\
\text { Flaps 0 } \\
\end{array}$ & $\begin{array}{l}\text { PF } \\
\text { PM }\end{array}$ & SELECT & \\
\hline
\end{tabular}

Figure 1. Manufacturer specific and process-based GA procedure.

\section{Developing parallel workflows}

The manufacturer procedure allocates different tasks and priorities to the PF and PM and highlights when and how information is shared at pre-defined times in the process.

Therefore, the workflows are interleaved. However, the respective workload of each flight crew member can limit effective interaction and monitoring (BEA, 2013). The process-based procedure implements a parallel workflow that focuses on achieving collaborative requirements of the flight crew at pre-defined times in the process. 


\section{Supporting adaptive task management}

The manufacturer procedure defines a linear workflow structured through process-gates that must be accomplished, or the task flow does not move forward. The redesigned procedure follows the process-based perspective and integrates an adaptive task management (ATM) concept allowing the flight crew to vary the task sequence according to the level of operational and environmental complexity in a prescribed way in this way. Functional action blocks which contain tasks are defined and these can be deployed in an adaptable way. The functional action blocks that can be reprioritised by the crew are ATM 1 (Configuration Change Management) and ATM2 (Flight Guidance). The ATM concept enhances the flexibility of the procedure in so-called disturbed GAs (BEA, 2013) that require immediate changes of the flight guidance modes.

\subsection{Evaluation of the new process centred procedure}

Based on SOP design guidelines (e.g. Degani \& Wiener, 1994; Degani et al., 1999; Loukupoulos et al., 2009; Barshi et al., 2016; Holder et al., 2016) we defined three design objectives to evaluate crew function allocations of both procedures in the three scenarios tested. The three key heuristics that the procedures are assessed against are the avoidance of concurrent task management, robust tasks sequencing and mature feedback loops.

\section{Concurrent task management}

Concurrent task management refers to the challenge imposed by multiple task demands competing for crew's attention and action (Loukupoulos et al., 2009). As the management of concurrent tasks can be vulnerable to human error (Loukupoulos et al., 2009), the design shall structure the task flow such that tasks requiring intensive resources are done with focus and without concurrent activities (Holder et al., 2016).Management of concurrent tasks can be challenging and vulnerable to human error, particularly during high operational demands. The manufacturer specified procedure causes concurrent task management, especially for 
the PM, when changing the configuration (flaps and landing gear) and when manipulating flight guidance modes during GA initiation.

This condition is exacerbated during the rejected landing. The take-off configuration warning disrupts the task sequence and captures crew's attention through verification of the warning (BEA, 2013). Concurrently, the PM monitors mode changes and system states while retracting flaps and landing gear. In both cases, flight path monitoring can be impaired if no flexible adjustment of the monitoring strategy in response to the task demands occurs (Anderson et al., 2017).

The impact on PM's ability to monitor the flight path is acute in the third and most complex scenario. The procedure sequence requires the PM to retract the flaps and landing before modifying the lateral and vertical flight guidance modes. Dehais et al. (2017) demonstrated that the attention shift when changing the configuration prevents the PM frequently from monitoring the flight path. The sub-optimal monitoring ability of the PM impacts safety considering that the flight guidance modes are not immediately modified. In this event, the PF can lose the cockpit aids to follow the correct trajectory while the PM is not able to monitor the flight path concurrently.

In contrast, the modified procedure prevents the PM from an attention shift away from the primary flight display (PFD) to the flap lever at GA initiation as this action is delayed by design. Likewise, through the ATM the PM can set own priorities in task execution to facilitate flight path monitoring and to support the PF through immediate changes of the flight guidance modes. The crew-centric design does not provide this flexibility and crews may be compelled to deviate from the procedure or reduce resource to monitor the flight path.

\section{Robust task sequence}

The task sequence refers to the order of actions that are interrelated, performed simultaneously and are time-dependent (Degani \& Wiener, 1994). A robust task sequence is resilient to changing and dynamic contexts such as those found in a GA manoeuvre. The 
task sequence of GA procedures require a dynamic interaction between flight crew members, external agents and aircraft systems. Therefore, the procedure sequence need to enable interaction patterns that evolve dynamic task management by the flight crew (Holder et al., 2016).

The task sequence of the manufacturer procedure has proven operational viability and airline pilots are usually familiar with it. However, the sequence of interactions is fairly tight, particularly when initiating the GA. In crew-centric the procedure indicates multiple interactions shown with arrows between the PF and PM as shown in Figure 2. The crew cooperation is based on 'command, action and response' The PF commands 'Go-Around Flaps' and the PM performs the required actions followed by a verbal response to notify the PF about the current system state. The response can also be silent: the PF announces the FMA (command) followed by a visual check of the PM (action). No aural response by the PM is necessary as long as the indication on the FMA corresponds to the callout of the PF.

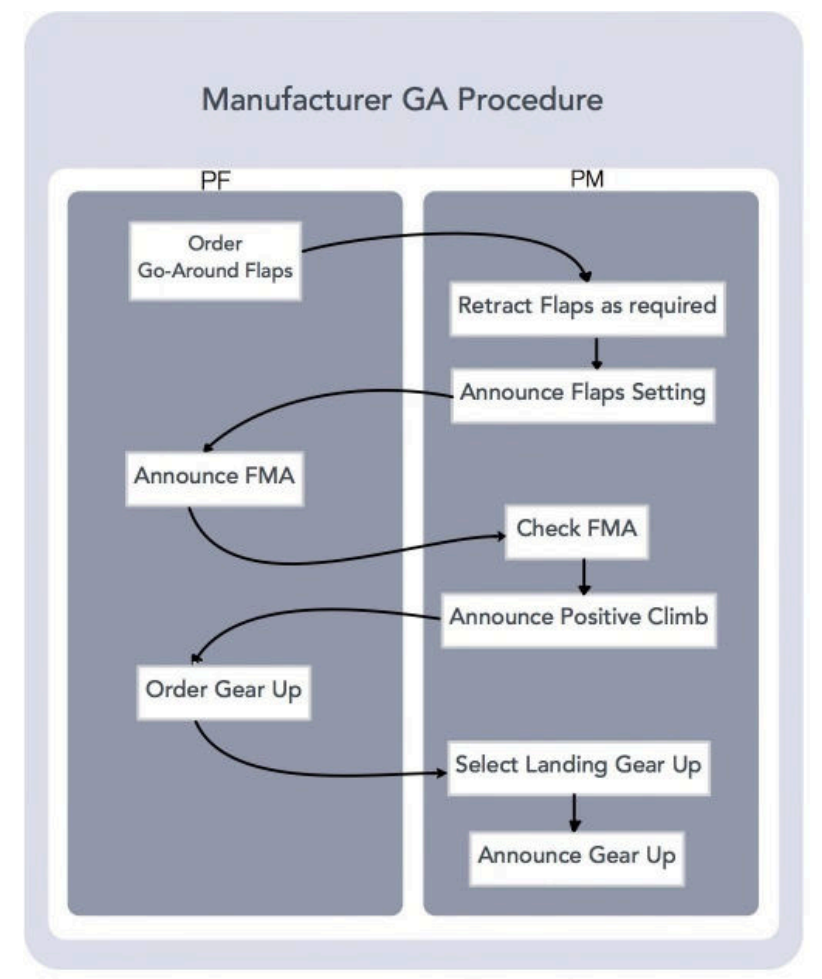

Figure 2. Crew interactions of the manufacturer SOP at GA initiation 
The second scenario tested demonstrates that the delay of the flap retraction may require a modification of the callout 'Go-Around-Flaps' to 'Go-Around'. The PF commands the flap retraction when the aircraft achieves the target pitch attitude (Airbus, 2005) which likely results in a delay of the FMA callout and gear retraction in comparison to the baseline scenario.

The third and most complex scenario, shows how the procedure sequence can impair prospective memory (Toglia \& McDaniel, 2016; Anderson et al., 2017) of the crew.

Prospective memory refers to the cognitive processes that are involved in remembering to perform activities that were previously deferred or interleaved (Loukupoulos et al., 2009). For example, when receiving the clearance by air traffic control, the PM may need to defer the task of entering in the new clearance to attend to the aircraft configuration. The PM must then remember to return to the deferred task and this can lead to errors where this return is omitted (Dismukes, 2012). The process-based approach allow flexibility in the management of tasks to avoid procedure driven time constraints which can impair prospective memory and subsequent performance (Einstein et al., 1997; McGann et al., 2002).

Figure 3 shows the modified, process-centred procedure. The arrows show the interactions between PM and PF as the procedure is completed by the crew. Compared to Figure 2, there are fewer interactions required. The tight cueing of crew interactions can be reduced through application of parallel workflows. Interactions between pilot flying and monitoring are modified: The FMA is still announced by the PF and checked silently by the PM similar to the crew centric design. However, the 'command-action-response' loops are removed when retracting flaps and landing gear shown by fewer connecting arrows across from PM to PF. In a parallel workflow, the PM is fully responsible for these tasks and the loops change from 'command-action-response' to 'action-inform'.

During a rejected landing, no adjustment of the task sequence and the standard callout 'GoAround' is necessary. The flap retraction is already delayed by the design so that pilots do not have to consider or decide on the flap setting while in the demanding and time 
constrained immediate response. The ATM provides the required flexibility to potentially reduce the time between receiving the clearance changing autopilot modes to manage the flightpath.

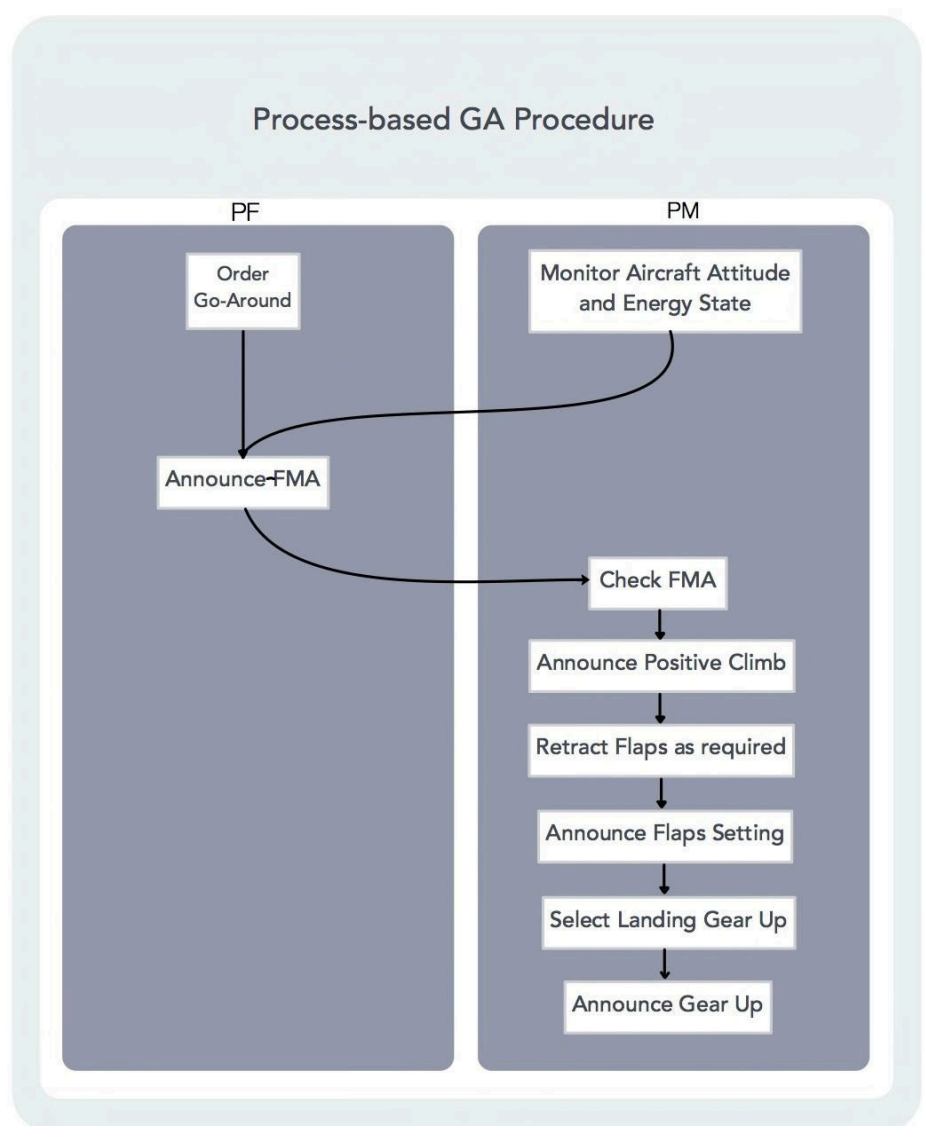

Figure 3. Crew interactions of the modified SOP at GA initiation.

\section{Mature feedback loops}

Feedback loops are considered mature if the timing within the workflow and content ensures sharing of the same understand of the state of the flight, future plans and actions required to configure the aircraft including automation (Kourdali \& Sherry, 2016a).

The feedback loops of the manufacturer procedure at GA initiation are mature but tightly cued. Therefore, the timing of actions demands optimal crew coordination (BEA, 2013). However, the timing is often controlled by other system agents (Pritchett et al., 2014) such as air traffic control. Feedback loops that are associated with configuration changes can be vulnerable to task interference and mis-ordering leading to reduced safety, for example mis- 
selection of the flap setting. The process-based procedure reduces the risk of overlaying status reports and commands by fully allocating the execution of the configuration change to the PM. Figure 4 shows that the PF remains in the loop through continuous status reports. The philosophy has changed from 'command-action-response' to 'action - inform'. The PM manages the timing of the configuration change and associated feedback to the PF. The feedback does not trigger a new interaction loop and flows without relying on mutual inputs. Therefore, while being in a dynamic situation, the configuration change can be performed fully independently, enhancing the robustness of the task sequence.
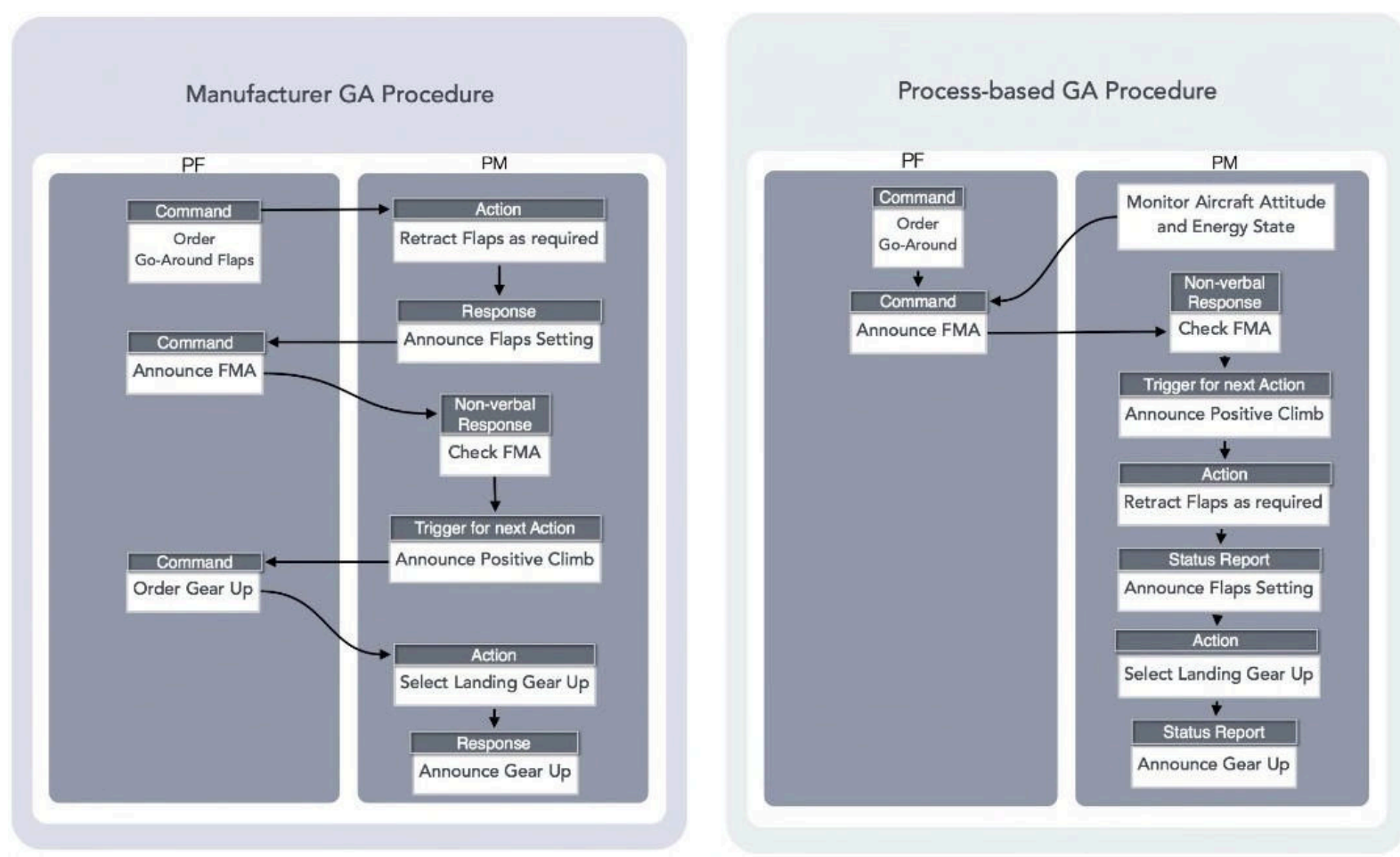

Figure 4. Feedback Loops at GA initiation.

However, we acknowledge that omitting status reports can affect the awareness of the PF related to the aircraft system states due to the one-way communication and parallel workflows (Degani \& Wiener, 1994). The enhanced flexibility may result in a mixture of individual actions rather than functional action blocks. This is a limitation of the processcentred procedure and will be explored in the empirical work. 


\section{METHOD}

\subsection{Design}

To address the aims of the study the new GA procedure was tested using a high-fidelity simulation across three different GA scenarios of differing levels of complexity. Pilots rated workload for three task groups for both the modified (process-centred) and unmodified (crew-centred) procedures. These task groups give further detail on the workload experienced during the procedure. These tasks groups follow the sequence of a go-around regardless of the procedure used and comprise immediate response, flight guidance and return to clean configuration. In the immediate response the go-around is called, the gear raised and the thrust increased. In the flight guidance task, a stable flight trajectory is achieved though management of autopilot/flight director modes. In the return to clean configuration flaps are fully retracted and a stable flight trajectory is assured by the crew.

Workload was assessed following each simulation by the PM and PF giving ratings on the Bedford Workload Rating Scale (BFRS) (Roscoe \& Ellis, 1990). The scale is easy to use (Roscoe, 1984) and provides a valid and reliable measure of workload (Corwin et al., 1989). Since the BFRS is not diagnostic (NASA, 2014), we report crew feedback and direct captured by the first-author during the simulations to understand what may have contributed to workload issues. Crew performance was also evaluated in regard to flight path management and procedure adherence.

\subsection{Participants}

All participants were ATPL qualified and gave informed consent to complete the study. All pilots were experienced on the Airbus A320. Table 2 shows the crew composition and total flight experience. 
Table 2 Participants and total flight experience.

Crew

Crew 1 (Airline Pilots)

Crew 2 (Airline Pilots)

Crew 3 (Test Pilots)
Flight Experience Captain

300 hours

9500 hours

7000 hours
Flight Experience First Officer 2500 hours

1450 hours

2900 hours

\subsection{Scenarios}

Three different GA scenarios were used to stimulate aircrew response: GA at minimum altitude, rejected landing and revised missed approach. All three scenarios capture different elements of the task, and all three require the GA SOP to be fully completed. The defined scenarios are operationally relevant since they are either part of the airline training or were already applied in other GA studies (e.g. BEA, 2013; Niedermeier \& Buch, 2016; Dehais et al., 2017). The scenarios rise in complexity with the revised missed approach (scenario 3) being the most operationally complex.

\section{Scenario 1: GA at minimum altitude}

The baseline scenario is the GA at minimum altitude due to a loss of the visual reference to the runway. The flight crew initiates the GA at minimum altitude and follows the published missed approach procedure as pre-programmed into the aircraft.

\section{Scenario 2: Rejected landing}

The second scenario is a rejected landing. A rejected landing is a GA upon touchdown when the thrust levers are set to idle and reversers must not be selected; if reversers are selected and deployed, GA is not possible (Airbus, 2005). No specific procedure is given for this manoeuvre. Instead, the manufacturer acknowledges that the rejected landing may require an adjustment of the task sequence since the flap retraction shall be delayed to provide sufficient lift until the aircraft achieves the target pitch attitude (Airbus, 2005). Finally, a take- 
off configuration warning may occur because the flap and trim set up at GA initiation does not correspond to the recommended configuration for take-off.

\section{Scenario 3: Revised missed approach}

The third scenario introduces an element of surprise by assigning a new missed approach including a revised heading (20 degrees offset to the runway) and a restrictive level off altitude (reduction by 50 per cent) at GA initiation. The scenario is similar to the study by Dehais et al. (2017) and the BEA (2013). The simultaneous climbing turn with an altitude limitation increases the temporal pressure and demands complex energy and flight path management (Dehais et al., 2017). Also, the flight crew cannot rely on the pre-programmed missed approach in the flight management system.

\subsection{Procedure}

We conducted three trials in cooperation with the DLR using the AVES A320 full-flight research simulator (Richter, 2014). The six participants as outlined in Table 2 performed the three scenarios using both types of procedure.

All crews manually controlled the aircraft at GA initiation and engage automated modes as required. Scenario order and procedure type order were counterbalanced across the participants to reduce practise effects Training scenarios before the test were conducted to familiarise participants with the simulator and workload questionnaire as recommended by Harris et al. (1992).

\section{RESULTS}

\subsection{Workload Assessment}

Figure 5 shows the plots of individual participant ratings of workload for the PF and PM applying the manufacturer versus the modified procedure across the three scenarios. Bedford workload scale ratings vary from 1 to 10 , a higher number indicating less spare capacity and therefore a higher level of workload being experienced. Table 3 combines the 
workload classifications and the overall distribution of BFRS scores across the three scenarios for both the manufacturer and modified procedure.
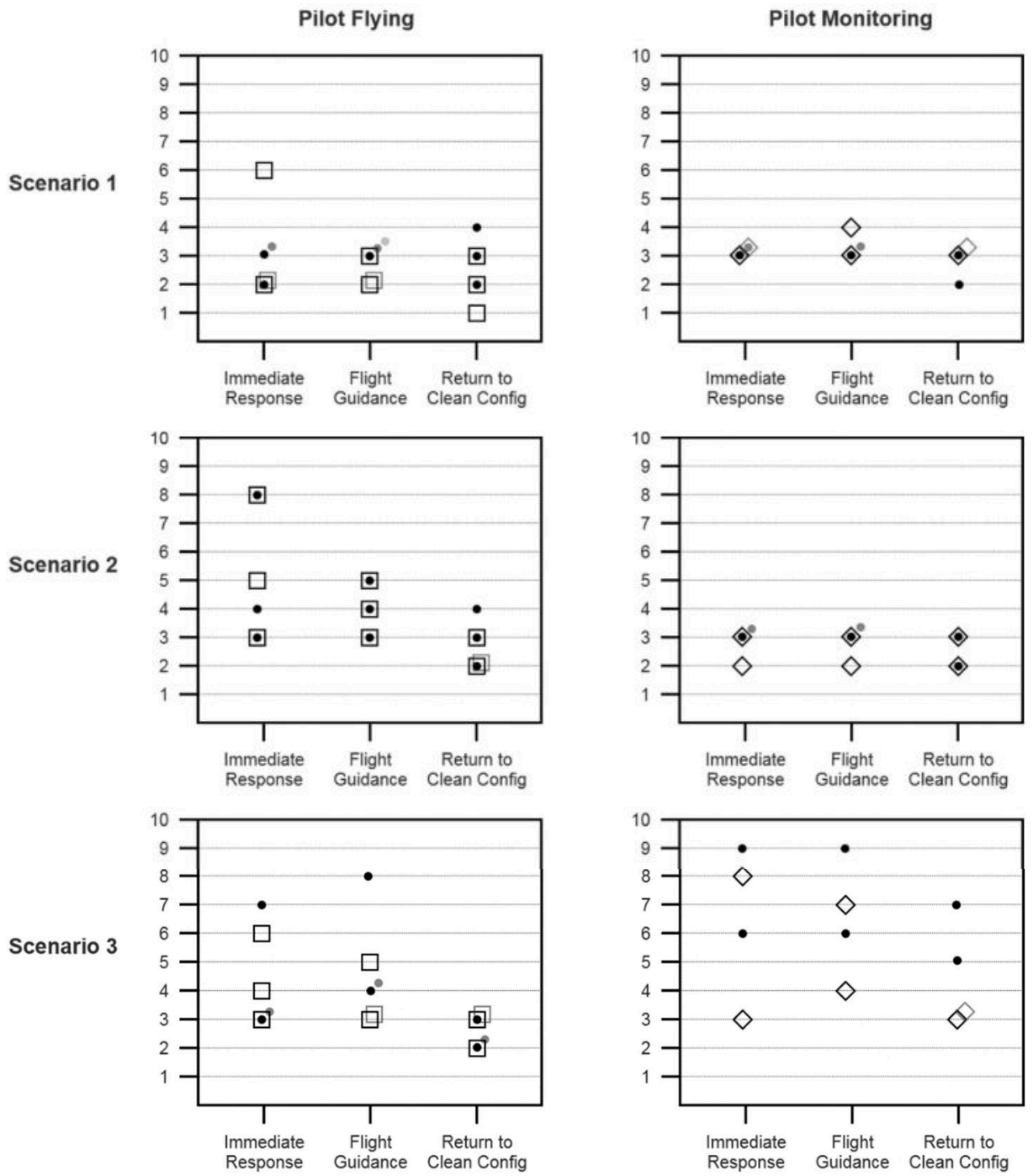

$$
\begin{array}{lll}
-\quad \text { Manufacturer PF } & \bullet & \text { Manufacturer PM } \\
\square \text { Modified PF } & \diamond & \text { Modified PM }
\end{array}
$$

Figure 5. BFRS ratings for the modified (unfilled) and unmodified (filled) procedures for PF and PM. All scores are whole numbers and jitter has been applied to distinguish multiple participants scoring the same workload. 
Table 3 Cumulative percentage of Bedford workload ratings for both procedures across the three scenarios and crew roles.

\begin{tabular}{lll}
\hline Workload Impact Classification & Crew-centred & Process-based \\
\hline Satisfactory (BFRS 1-3) & 65 & 73 \\
\hline $\begin{array}{l}\text { Unsatisfactory but Tolerable (BFRS 4-6) } \\
\begin{array}{l}\text { Not tolerable but possible to complete the } \\
\text { task }\end{array}\end{array}$ & 22 & 20 \\
\hline Task Not completed & 0 & 7 \\
\hline
\end{tabular}

Workload ratings indicate broadly increasing workload for both flight crew members and both procedures across the scenarios from one to three. This finding is in the expected direction since the complexity of the GA manoeuvres increases through the scenarios. Workload Scores for both flight crew members are higher during immediate response and when changing flight guidance modes compared to the return to clean configuration after passing the thrust reduction altitude. The flight crews indicated a higher cumulative percentage of workload ratings between 1 and 3 (lower workload) when applying the process-based design across the three scenarios compared to the manufacturer, crew-centric procedure. The cumulative percentage of workload ratings at or above 7 (higher workload) is also lower when applying the process-based design.

Considering the first scenario, flight crew workload is satisfactory without reduction for both procedures tested. We cannot claim noteworthy benefit for the new procedure in scenario 1 based on the results. However, we note that, except for one rating during immediate response, the process-based design some participants have rated workload lower when operating as the PF. PM workload across the task groups is broadly similar. Scenario 2 presents a similar pattern of results and there is no compelling trend towards either higher or lower workload for either procedure regardless of role or task section. In scenario 3, the most complex of the three scenarios tested, there is evidence that workload is reduced when using the new, process-based procedure in contrast to the manufacturer specified 
procedure. Overall, workload is reported as tolerable but lower workload is reported across the three tasks and the two roles when using the new procedure. We observed that flight crew activated the heading mode and selected a lower go-around altitude in scenario 3 more quickly when applying the adaptive task management. Pilot feedback confirmed that lower workload ratings can be attributed to faster changes of flight guidance modes by the PM when initiating the go-around compared to the crew-centric design.

\subsection{Crew performance assessment}

\section{Flight path management}

In scenario 1 and 2, no deviations from altitude or heading were observed using either procedure. In scenario 3, minor deviations from the desired heading were observed when crews used the process-based procedure. One explanation for this is the ATM concept applied to the process based procedure. Given reprioritisation of tasks delay in changing the autopilot modes, these minor deviations may have occurred. However, these minor deviations did not adversely affect flight safety and the procedure was successfully concluded. When using the manufacturer, crew-centric procedure, two crews did not fly the correct heading due to improper configuration of autopilot modes. One explanation for this is the time constraints impacting prospective memory which are evolved when using the crewcentred approach where tasks may be deferred and then recalled.

\section{Crew co-ordination}

A common crew co-ordination issue was observed for both procedures tested, across all scenarios. Using both procedures, in at least one scenario, we observed each crew performing an early flap retraction towards clean configuration prior to reaching the thrust reduction altitude, as prescribed by both procedures. This is problematic for the processbased approach since this approach lacks the high level of interaction, backwards and forwards between PM and PF. In the crew-centred approach the cross-checking quickly revealed the early flap retraction. In the process-based procedure there is no command by 
the PF. Although there is the opportunity in the procedure for the PF to call 'hold-flaps, this was not employed by any PF during the simulator trials. However, from observation there is also evidence that parallel workflows potentially cause a detriment of cross-checking and specific focus of the PF on the primary flight display due to the new function allocation. This observation was confirmed by pilot feedback. This represents a one risk when using parallel workflows that must be considered if a process-based approach is adopted. This risk must be balanced with the reduced task overlays which are produced when using the crewcentric, manufacturer approach.

\section{Procedure adherence}

The process-approach gives flexibility through the use of the ATM concepts: groups of tasks that can be deployed as needed. In the process-based procedure designed in this article, two groups were defined: ATM1 and ATM 2. In simulator trials, we twice observed a 'runaway effect' where two PMs would go beyond the specified task groups. This is not how the ATM concept should be used. This behaviour could arise from a lack of familiarity with the procedure or indeed a suboptimal design. This is an important result since pilots may go beyond the boundary of the process-based philosophy when implementing flexible workflows. Figure 6 shows one example of a PM moving tasks between the ATM blocks. In this example tasks from ATM1 are completed within ATM 2 and vice-versa. Pilot feedback indicates that disconnecting tasks from their ATMs causes unpredictability of the workflows performed by the PM. This may lead to confusion and reduced performance. 


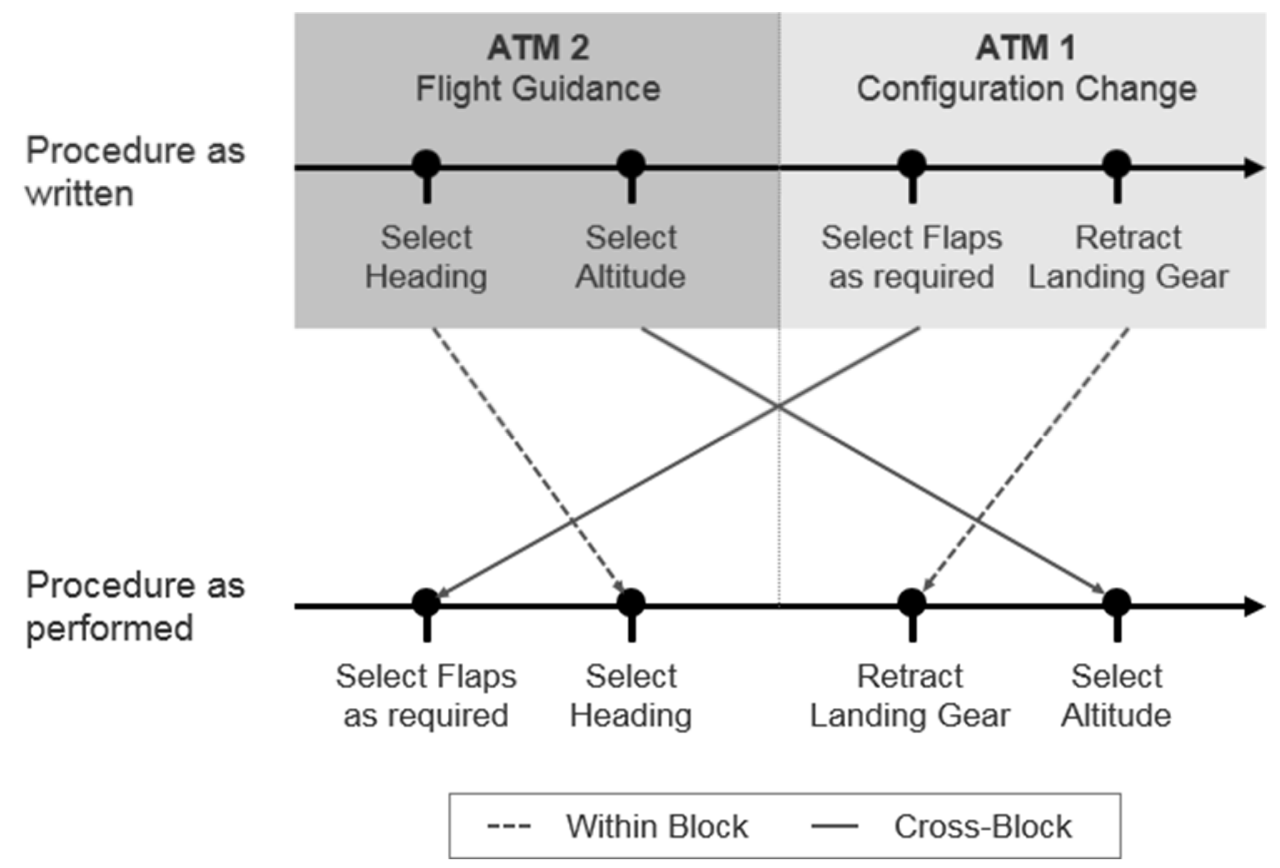

Figure 6. One example observed from a PM of combining tasks in opposing ATMs.

\section{DISCUSSION}

In this research we have evolved a process-based procedure for GA management from the manufacturer specified, crew-centric procedure. We have found evidence of reduced workload using the process-based procedure in the most complex GA scenario tested in the simulator. We have also found that pilots have favourable views of the new procedure. We have extended the theoretical work conducted by Cahill et al. (2014) into a translation of a crew-centric procedure into a process based procedure.

One explanation for our workload findings concerns that demand for concurrent task management in the crew-centric procedure. This concurrent management of tasks could affect the PM ability to monitor the rapidly changing flight situation in a complex GA. This explanation is supported by other research which has suggested that the use of the crewcentric procedure demands a wide allocation of visual attention (BEA, 2013; Dehais et al., 2017). These studies also report flight path deviations which are explained by complex interaction with the flight management system concurrently with the monitoring role. These reported findings concur with or workload ratings in the most complex scenario demanding new flightpath information being entered into the aircraft systems. 
In contrast, the process-based approach suggests beneficial effects on flight path monitoring and management. In addition a reduction in workload in the most complex scenario was observed. Flight path monitoring by the non-flying pilot was further facilitated by the adaptive-task management concept which allows setting own priorities in task execution. Through reducing operational complexity by simplifying lower priority tasks supports flight path monitoring in the critical stages of the GA. To maintain safe operation in a disturbed GA, we emphasise the need described by Cahill et al. (2014) that procedure design needs to go beyond linear workflow accounts to ease the procedure execution. Through the ATM concept, we demonstrated that this approach is feasible. Participant response in regard to the ATM concept was positive, providing the ability of crew members to align the procedure sequence with the operational context, providing choice rather than mandatory instruction (Carim et al., 2016).

The crew-centred GA procedure can be executed smoothly providing flight crew are proficient in coordinating their tasks and share information at the pre-defined process gates. However, the results of the procedure evaluation reflect the observed flight crew performance. The tight cueing of feedback loops can results in frequent overlay of status reports and commands even at a satisfactory level of workload, potentially risking operational safety. Our findings in the simulator trial add to evidence that co-ordination is challenging in the GA manoeuvre (Dehais et al., 2017; BEA, 2013). As with many procedures, the design can be represent an idealised 'work as imagined' description of task demands together with the assumption of being applied in a static, rather than dynamic environment as is the case with the GA manoeuvre (Surabatulla et al., 2019). This situation may impact upon compliance with the procedure as written. Crew workarounds and delayed actions may result from a rigidly designed procedure that is not responsive to the context of a given operational demand. The process-centred approach may deliver a controlled level of flexibility that captures context more effectively and mitigates non-compliance with an overly rigid, crew-centred SOP. 
Conversely, it would be incorrect to suggest that current, procedure design is fundamentally flawed. Procedure design is conducted with reference to risk and is part of a wider safety assessment of cockpit operations. Our results indicate that parallel workflows can result in an inadvertent flap retraction before reaching the thrust reduction altitude using the process based approach. One explanation for this finding is the reduced cross-checking in the process centred procedure resulting in reduced co-ordination. However, our results support further examination of how the process-based procedure could have a positive impact on more complex, dynamic operations, such as GA. Clearly any implementation of a new procedure would need to be subject to the same hazard and risk analyses applied to the current manufacturer procedures.

Naturally, our research has limitations. Our findings are supported by a small sample that does not allow for statistical generalisation. However, our sample does comprise trained pilots and as such we do claim validity for our results but caution is needed in interpretation. In addition, we acknowledge a degree of opacity in the design of the new, process based procedure. We have attempted provide clarity in the design decisions that we have made and these are explicated further in the electronic supplementary material. There is however, a degree of creativity when translating a crew-centric to a process based procedure that is difficult to proceduralise. We hope that the overarching design principles that we have applied are helpful in this regard. Finally, we have tested a single flight manoeuvre among the many that are demanded in flight.

To conclude, this article has begun to open up the possibility of changing our approach to procedures. Of course we do not advocate, and cannot evidence, wholesale transition from one philosophy to another. Future research may identify those procedures that would benefit from the process-based approach. It may be that the style of procedures that can be adjusted safely by taking into account new innovations in the cockpit, particularly decision support when conducting procedures. Future research may begin to include these new 
innovations to ensure that procedures always help, rather than hinder performance in the most demanding flight manoeuvres and operations.

\section{CONLFICT OF INTEREST}

The authors have no conflicts of interest to report.

\section{ACKNOWLEDGEMENTS}

The authors would like to thank Per Ohme, Dominik Niedermeier and Jan Phillip Buch of the German Aerospace Center (DLR) for their superlative technical support in conducting the simulator campaign. Also, we appreciated the support and feedback by all airline and test pilots who participated in this study.

\section{REFERENCES}

AAIB, Air Accident Investigation Branch 2016a. Airbus A 319-111 G-EZTZ, EW/G2016/20/11. AAIB Bulletin 8: 2729.

AAIB, Air Accident Investigation Branch 2016b. Airbus A 320-214 G-EZTZ, EW/G2016/20/11. AAIB Bulletin 8: 3031.

Airbus 2005. Flight Operations Briefing Notes - Landing Techniques - Bounce Recovery Rejected Landing. Toulouse, France.

Airbus 2006. Flight Operations Briefing Notes - Standard Operating Procedures - Operating Philosophy. Toulouse, France.

Airbus 2017a. A Statistical Analysis of Commercial Aviation Accidents 1958-2017. Toulouse, France.

Airbus 2017b. A320 Flight Crew Training Manual. Toulouse, France.

Anderson, F., McDaniel, M. A. and Einstein, G. O. 2017. Remembering to Remember: An Examination of the Cognitive Processes Underlying Prospective Memory. In Stein, O. (ed.) Reference Module in Neuroscience and Biobehavioural Psychology. Elsevier: 2-11. 
ATG, Aeronautical Training Group 1999. Training Notes Airbus A320 - Book 2 - Airbus A320 Avionics Systems - Navigation and Autoflight. Luton, Bedfordshire, UK.

ATSB, Australian Transport Safety Bureau 2007. Go-around Event Melbourne Airport, Victoria, 21 July 2007, VH-VQT, Airbus A320-232, ATSB Transport Safety Report AO-2007044 Final. Canberra City, Australia.

ATSB, Australian Transport Safety Bureau 2014. Flap overspeed and altitude exceedance during go-around Airbus A321, VH-VWY, Carins Airport, Queensland, 3rd September 2012, ATSB Transport Safety Report AO-2012-116. Northbourne, Australia.

Barshi, I. and Healy, A. 1993. Checklist, procedures and the cost of automaticity. Memory \& Cognition 21(4): 496-505. Available at:

https://link.springer.com/article/10.3758/BF03197181.

Barshi, I., Mauro, R., Degani, A. and Loukopoulou, L. 2016. Designing Flightdeck Procedures, NASA/TM-2016-219421. Moffett Field, California: NASA Ames Research Center.

BEA, Bureau d'Enquêtes et d'Analyses 2000. Accident Investigation Report, Gulf Air Flight GF-072, 23.08.2000. Le Bourget, France.

BEA, Bureau d'Enquêtes et d'Analyses 2007. Final report on the investigation into the accident involving the Armavia A320 near Sochi Airport on 3 May 2006. Le Bourget, France.

BEA, Bureau d'Enquêtes et d'Analyses 2009. Rapport Incident grave survenu le 23 septembre 2009 sur l'aérodrome Paris Charles de Gaulle (95) à A 319-111 immatriculé FGRHU. Le Bourget, France.

BEA, Bureau d'Enquêtes et d'Analyses 2013. Study on Aeroplane State Awareness during Go-Around. Le Bourget, France. 
Blajev T. \& Curties W. 2017. Go-Around Decision Making and Execution Project. Flight Safety Foundation. Available at: https://flightsafety.org/wp-content/uploads/2017/03/Goaround-study_final.pdf (Accessed: 28th April 2019).

de Brito, G. 1998. Study of the use of airbus flight deck procedures and perspectives for operational documentation. International Conference on Human Computer Interaction in Aeronautics (HCl-Aero 98), Ecole Polytechnique de Montréal, Canada: 195-201.

Cahill J., Callari, T.C., Fortmann, F., Suck, S., Javaux, D., Hasselberg, A. and Stoeve S. H. 2017. Adaptive Automation and the Third Pilot: Managing Teamwork and Workload in an Airline Cockpit. In: Longo, L. and Chiara Leva, M. (eds). Human Mental Workload, Models and Applications, First International Symposium, H-Workload 2017, Dublin Ireland, June 2830, 2017: 161 - 173. Available at: https://link.springer.com/chapter/10.1007\%2F978-3-31961061-0_10.

Cahill, J., McDonald, N. and Losa, G. 2014. A Sociotechnical Model of the Flight Crew Task, Human Factors 56(8): 1337-1363. Available at: https://doi.org/10.1177/ 0018720814532684.

Carim Jr. G.C., Saurin T.A., Havinga J., Rae A., Dekker S. and Henriqson E. 2016. Using a procedure doesn't mean following it: A cognitive systems approach to how a cockpit manages emergencies, Safety Science 89: 147-157. Available at: https://doi.org/10.1016/j.ssci.2016.06.008.

Corwin, W.H., Sandry-Garza, D.L., Biferno, M.H., Boucek, G.P., Logan, A.L., Jonsson J. E. and Metalis, S.A. 1989. Assessment of crew workload measurement methods, techniques and procedures, Vol. 1 - Process, methods and results (WRDC-TR-89-7006). Wright Patterson Air Force Base, $\mathrm{OH}$.

Degani, A., Heymann, M. and Shafto, M. 1999. Formal Aspects of Procedures: The Problem of Sequential Correctness. Proceedings of the Human Factors Ergonomics Society 43rd Annual Meeting, TX, 43(20): 1113-1117. Available at: https://doi.org/10.1177/154193129904302012. 
Degani, A. and Wiener, E. L. 1994. On the Design of Flight-Deck Procedures. Moffett Field, California: NASA Ames Research Center.

Degani, A. \& Wiener, E. L. 1997. Procedures in complex systems: The airline cockpit. IEEE Transaction on Systems, Man and Cybernetics 27(3): 302-312. Available at: doi:10.1109/3468.568739.

Degani, A. \& Wiener, E. L. 1998. Design and operational aspects of flight-deck procedures. Proceedings of the International Air Transport Association (IATA) Annual Meeting, Montreal, Canada, 1998.

Dehais, F., Behrend J., Peysakhovich, V., Causse, M. and Wickens, C.D. 2017. Pilot Flying and Pilot Monitoring's Aircraft State Awareness During Go-Around Execution in Aviation: A Behavioural and Eye Tracking Study. The International Journal of Aerospace Psychology 27(2): 1528. Available at: http://dx.doi.org/10.1080/10508414. 2017.1366269.

Dismukes, R. K. 2012. Prospective Memory in Workplace and Everyday Situations. Current Directions in Psychological Science 21(4): 215-220. Available at: https://doi.org/10.1177/0963721412447621.

Drury, C.G.1998 Case study: error rates and paperwork design. Applied Ergonomics, Volume 29, Issue 3, Pages 213-216, doi.org/10.1016/S0003-6870(97)00049-5.

Drury, C.G., Barnes C.D., Bryant M.R. 2017a. Why do we STILL not Follow Procedures? Proceedings of the Human Factors and Ergonomics Society 2017 Annual Meeting 61(1). 1664-1668. Available at: https://doi.org/10.1177/1541931213601904.

Drury, C.G., Barnes C.D., Bryant M.R. (2017b). Failure ot Follow Written Procedures . DOT/FAA/AM-17/17. FAA, Washington.

Drury, C. G., \& Johnson, W. B. (2013). Writing aviation maintenance procedures that people can /will follow. Proceedings of the Human Factors and Ergonomics Society Annual Meeting 57(1). 997-1001. doi.10.1177/1541931213571223 
Einstein, G. O., Smith, R. E., McDaniel, M. A. and Shaw, P. 1997. Aging and prospective memory: The influence of increased task demands at encoding and retrieval. Psychology and Aging 12(3): 479-488. Available at: http://psycnet.apa.org/doi/10.1037/08827974.12.3.479.

FAA, Federal Aviation Authority 2003. Standard Operating Procedures for Flight Deck Crewmembers. Advisory Circular No. 120-61A. Washington, DC: US Department of Transportation. Washington, DC: US Department of Transportation.

Funk, K., Mauro, R. and Barshi, I. 2009. NextGen flight deck human factors issues.

Proceedings of the 15th International Symposium on Aviation Psychology, Dayton, $\mathrm{OH}$ : 208213.

Go-around (GA) Safety Forum 2013. Go-around Safety Forum 18 June 2013 Brussels: Findings and Conclusion. Brussels: Flight Safety Foundation, European Regions Airline Association, Eurocontrol.

Granger, S. and Jeanpierre, E. 2011. Automatic NAV engagement at Go Around. Safety First - The Airbus Safety Magazine (11): 19-21.

Harris, R.M., Hill, S.G., Lysaght, R.J., and Christ, R.E. 1992. Handbook of operating the OWL \& NEST technology (ARI Research Note 92-49). Alexandria, VA: United States Army Research Institute for the Behavioural Social Science.

Holder, B., Jacobson, A., Nikolic, M., Whitlow, S. 2016. Flight Deck Task Management, White Paper DOT/FAA/TC-17/16. Washington DC: US Federal Aviation Administration. Hradecky, S. 2017. Incident: Easyjet A320 at Paris on March 2017, inadvertent flaps retraction on takeoff, The Aviation Herald. Available at: http://avherald.com/h?article $=4 a 741 c 67$ (Accessed: $8^{\text {th }}$ July 2020). 
Jones C., Phillips D., Ashcraft D. 2018. Understanding procedural violations using Safety-I and Safety-II: The cause of community pharmacies, Safety Science, 105: 114-120. Available at: https://doi.org/10.1016/j.ssci.2018.02.002.

JTSB, Japan Transport Safety Board 2016. Aircraft Accident Investigation Report AA2016-9, Asiana Airlines Inc. Flight HL 7762, Hiroshima Airport on 14 April 2015.Tokyo, Japan.

Kemeny, C. J. and Popp, C. 2016. One Team, Journal for Civil Aviation Training (CAT) 27(2): 26-28.

Kingdom of Bahrain Civil Aviation Affairs (CAA) 2000. ACCIDENT INVESTIGATION REPORT Gulf Air Flight GF-072 Airbus A320-212, REG. A40-EK on 23 August 2000 at Bahrain.

Kourdali, H. K. \& Sherry, L. 2016a. A Comparison of Two Takeoff Flap Retraction Standard Operating Procedures. Integrated Communications Navigation and Surveillance (ICNS), 2016, Herndon, VA, USA. Available at: doi:10.1109/ICNSURV.2016.7486344

Kourdali, H. K. \& Sherry, L. 2016b. A Systems Engineering Method and Simulation of Standard Operating Procedures. $\mathrm{HCl}$-Aero '16 Proceedings of the International Conference on Human-Computer Interaction in Aerospace, Article No. 13, Paris, France - September 14 - 16, 2016. Available at: https://doi.org/10.1145/2950112.2964580.

Kourdali, H. K. \& Sherry, L. 2017. Available Operational Time Window (AOTW): A Method for Evaluating Airline Standard Operating Procedures. Journal of Cognitive Engineering and Decision Making 11(4): 371-381. Available at: https://doi.org/10.1177/1555343417727190.

Lefrancois, O., Matton, N., Gourinat, Y., Peysakhovich, V., Causse, M. 2016. The role of pilots' monitoring strategies in flight performance. Paper presented at the European Association for Aviation Psychology Conference, Cascais, Portugal. 
Liu, H., Ma, X., Zhang Y. and Jin, Z. 2017: Practice for the Certification of Minimum Flight Crew Workload. HCI International 2017 - Posters' Extended Abstracts, 19th International Conference, Vancouver, BC, Canada, July 914: 339-346.

Loukupoulos, L. D., Dismukes, R. K. and Barshi, I. 2003. Concurrent task demands in the cockpit, challenges and vulnerabilities in routine flight operations. Proceedings of the 12th International Symposium on Aviation Psychology: 737-742.

Loukupoulos, L. D., Dismukes, R. K. and Barshi, I. 2009. The Multitasking Myth - Handling Complexity in Real-World Operations. Aldershot, UK: Ashgate.

Maille, N. 2016. Modeling Airline Crew Activity to Improve Flight Safety Analysis. 38th IEEE Aerospace Conference, Big Sky, MT United States. Available at: https://hal.archivesouvertes.fr/hal-01383972.

Marconnet, D. \& Roland, M. 2014. Flying a Go-Around Managing Energy. Safety First - The Airbus Safety Magazine (17): 19-22.

Mauro, R., Degani, A., Loukopoulos, L. and Barshi, I. 2012. The Operational Context of Procedures and Checklists in Commercial Aviation. Proceedings of the Human Factors and Ergonomics Society 56th Annual Meeting - 2012. Available at: doi:10.1177/1071181312561158.

McGann, D., Ellis, J. A. and Milne, A. 2002. Conceptual and perceptual processes in prospective remembering: Differential influence of attentional resources. Memory and Cognition 30(7): 1021-1032. Available at: https://doi.org/10.3758/ BF03194320.

NASA, National Aeronautics and Space Administration 2014. Human Integration Design Processes (HIDP) - NASA/TP-2014-218556. Houston, Texas: NASA.

Niedermeier D. \& Buch, J.P. 2016. Das Man4Gen Projekt: Unterstützung von Airline- Crews in unerwarteten Situationen. Deutscher Luft- und Raumfahrtkongress 2016: 13-15. 
Norden, C. 2010. Go-around handling. Safety First - The Airbus Safety Magazine (10): 1213.

Owens, D. 2011. The Go-Around Procedure. Safety First - The Airbus Safety Magazine (12): $10-22$.

Owens, D. 2013. The Golden Rules for Pilots Moving from PNF to PM. Safety First - The Airbus Safety Magazine (15): 5-7.

Patel S, Drury C G , Lofgren J.1994 Design of workcards for aircraft inspection, Applied Ergonomics, Volume 25, Issue 5, Pages 283-293, doi.org/10.1016/0003-6870(94)90042-6.

Pélegrin, C. 2007. Compliance to operational procedures: Why do well trained and experienced pilots not always follow procedures?. Safety First - The Airbus Safety Magazine (5): 20-23.

Pritchett, A. R., Kim, S. Y. and Feigh, K. M. 2014. Measuring Human-Automation Function Allocation. Journal of Cognitive Engineering and Decision Making 8(1): 52-77. Available at: https://doi.org/10.1177/1555343413490166.

Rabl A. N., Billeriss C., Kellerer J. P., Simmat S. and Augsbach J. 2018. DON'T PANIC! Perform Complex Hierarchical Task Analysis with Airbus' eXtended HTA Tool. Proceedings of the $33^{\text {rd }}$ Conference of the European Association for Aviation Psychology. Groningen, Netherlands.

Richter, H.-L. 2014. Outbound flight to the future. DLR Magazine (140-141): 37-39.

Roscoe, A.H. 1984. Assessing Pilot Workload in Flight. Flight Test Techniques AGARD No 373, Proceedings of the Flight Mechanics Panel Symposium Held in Lisbon, Portugal on 35 April 1984. Advisory Group for Aerospace Research and Development, Neuilly-sur-Seine: $12-1-12-13$ 
Roscoe, A. H. \& Ellis, G. A. 1990. A Subjective Rating Scale for Assessing Pilot Workload in Flight: A Decade of Practical Use, Technical Report TR 90019. Farnborough, UK: Ministry of Defence.

Surabatulla D., Landry S.J. and Caldwell B.S. 2019. Evaluating and designing procedures in safety critical environments: a framework and taxonomy based on a critical review and synthesis. Theoretical Issues in Ergonomics Science. Available at:

https://doi.org/10.1080/1463922X.2018.1529205.

de Terssac, G. \& Chabaud, C. 1990. Référentiel opératif commun et fiabilité'. In Leplat, J. and de Terssac, G. (eds) Les facteurs humains de la fiabilité dans les systèmes complexes. Tolouse, France: Octarès: 111-139.

Toglia, J. \& McDaniel, M. A. 2016. Prospective Memory. In Strobach, T. and Karbach, J. (eds) Cognitive training: An overview of features and applications. Heidelberg, New York: Springer: 81-91.

Wainright, W.A. 1987. Flight test evaluation of crew workload, In Roscoe A.H. (ed.) The practical assessment of pilot workload, AGARDograph No. 282. Neuilly sur Seine, France: 60-68. 


\section{Evaluating process-based and crew- centred approaches to procedure design in aviation: workload and performance changes in go-around manoeuvres.}

Tim André Schmidt, Houda Kerkoub Kourdali and Jim Nixon

\section{Electronic Supplementary Material}

This additional material provides a detailed overview of the flight crew function allocations (task sharing design) of both procedures. The material clarifies and documents the design decisions made to create the new procedure. The designs are divided into the three principles that were used to create the process-centred procedures: simplifying configuration management, developing parallel workflows and supporting adaptive task management

\section{Simplifying configuration management}

To simplify configuration management to increase the PM's monitoring ability we adjust the procedural steps associated with flap-retraction during GA. Figure 1-A shows that the manufacturer procedure requires to retract the flaps by one step at GA initiation before checking the Flight Mode Annunciator (FMA) located above the Primary Flight Display (PFD). Thereafter, the PM calls for "Positive Climb" which is the trigger for the PF to command the gear retraction. The PM conducts the entire aircraft configuration change process. However, these tasks can be time-consuming during the GA and often undertaken to the detriment of flight path monitoring (BEA, 2013). 


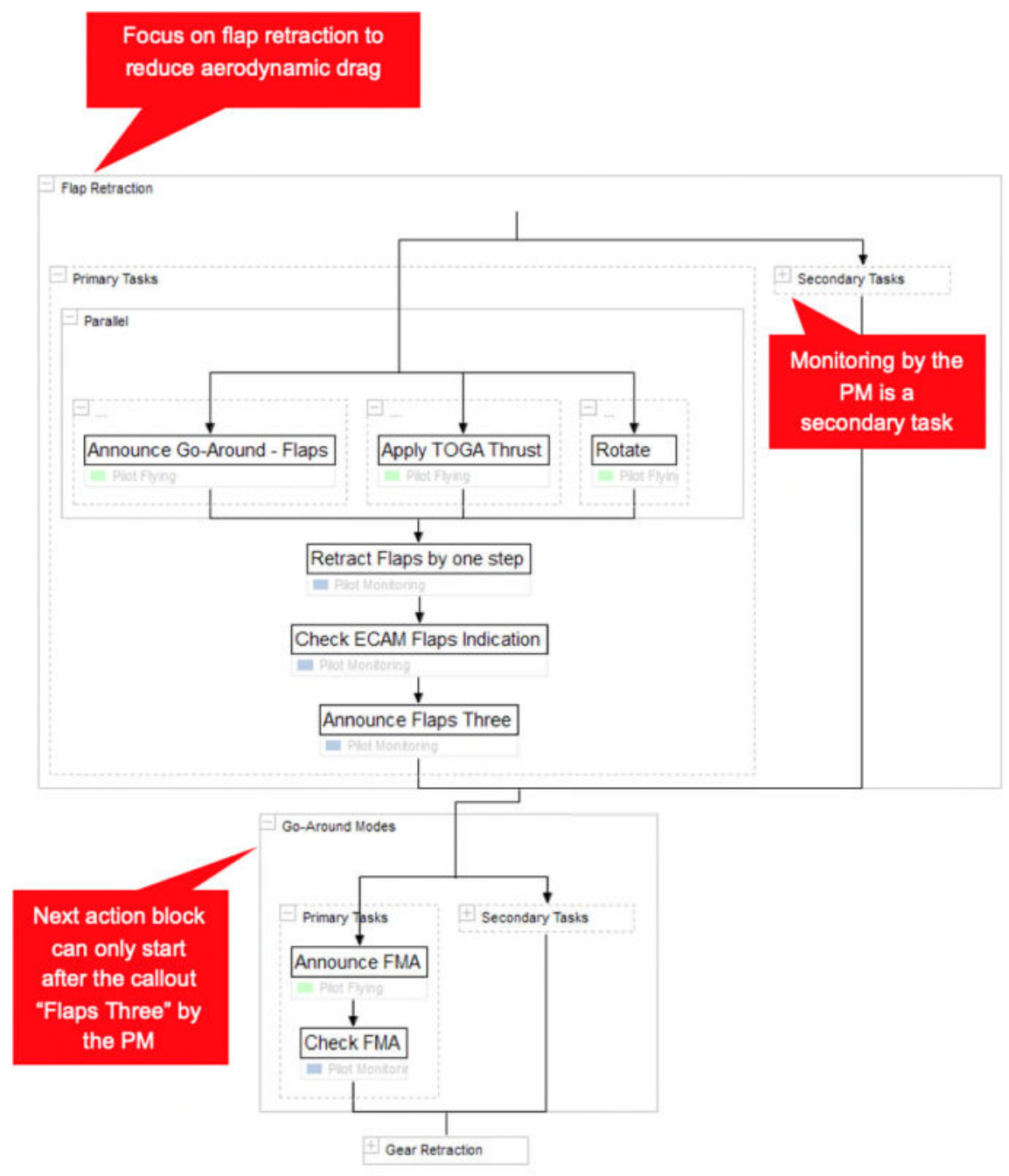

Figure 1-A. Manufacturer GA SOP with focus on aircraft configuration change at GA initiation In the modified procedure, we delayed the flap retraction after the "Positive Climb" callout. In doing so, this callout is no longer attached to the gear retraction. Rather, Figure 1-B shows that the callout triggers the adaptive task management shown as ATM1 or ATM2. 


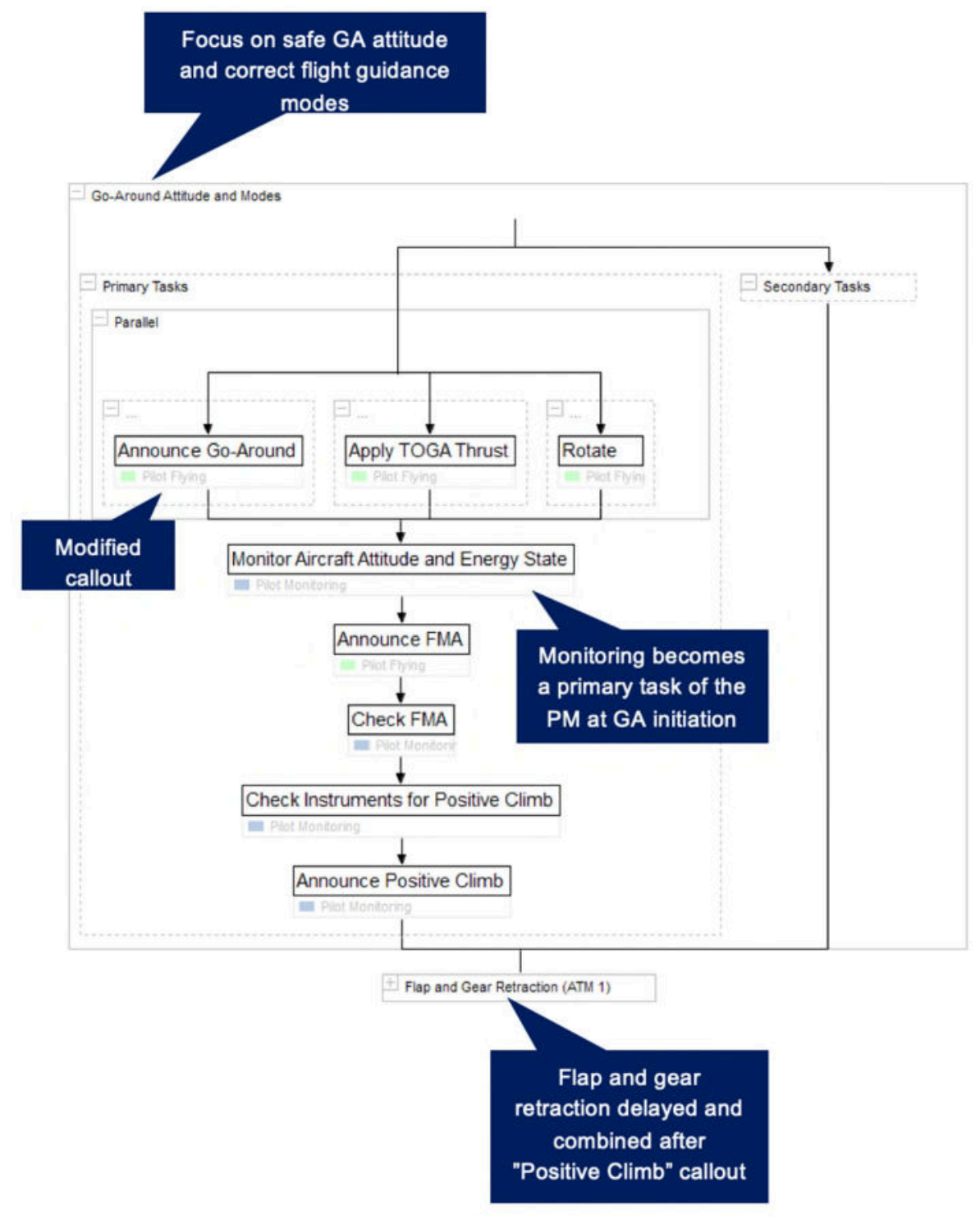

Figure 1-B. Modified GA SOP with focus on safe GA attitude and correct flight guidance modes at GA initiation.

The decision to delay the flap retraction is based on taking advantage of the available operational time window (AOTW) i.e. the time in which the procedure must be completed (Kourdali \& Sherry, 2017).

We use this time window to apply the idea by Degani \& Wiener (1994) that crew activities own different criticality levels. To identify those tasks with a high-criticality level, we referred to the analysis of 25 GA events conducted by the European Coordination Centre for accident and incident reporting system (ECCAIRS) (BEA, 2013). The analysis revealed significant 
lacks in flight path monitoring of pitch, thrust and airspeed notably by the PM (BEA, 2013). Therefore, we follow the ECCAIRS and rated flight path monitoring as a fundamental task with a high criticality level to prevent a loss of state awareness during GA. By decoupling the flap retraction from the GA initiation, we use the AOTW to provide free space for a new task explicitly referenced as "Monitoring Aircraft Attitude and Energy State" performed by the PM. Also, we included the FMA callout into this AOTW which is triggered by the PF. In doing so, monitoring of pitch, thrust and airspeed becomes a primary task of the PM until the aircraft is on a safe GA profile and the PF feels comfortable to callout the FMA.

The prioritisation of these tasks needs to be balanced against the impact of the delayed flap retraction on aircraft performance and manoeuvrability. Therefore, during the design phase of the modified procedure, we assessed the impact in both normal and contingency operations in a full-flight A320 simulator together with test pilots in several trials. Analysing flight data and pilot feedback confirmed no concern regarding aircraft performance and manoeuvrability during normal operation with all engines operative (AEO). However, with one-engine-inoperative (OEI) we determined a significant reduction of airspeed when flying the manufacture's recommended pitch of 12.5 degrees (Airbus, 2017b). The airspeed stabilised slightly above the lowest selectable speed (VLS) for autopilot and autothrust when initiating the GA. Even when staying above the 1-g stalling speed, the OEI performance was assessed as unsatisfactory. Therefore, the scope of this study is limited to normal operations with AEO.

\section{Developing Parallel Workflows}

The motivation for the design of parallel workflows was to improve the interaction and mutual monitoring of flight crew actions. Figure 2 shows that we fully allocated the configuration change to the PM without prior command of the PF when retracting flaps and landing gear. 


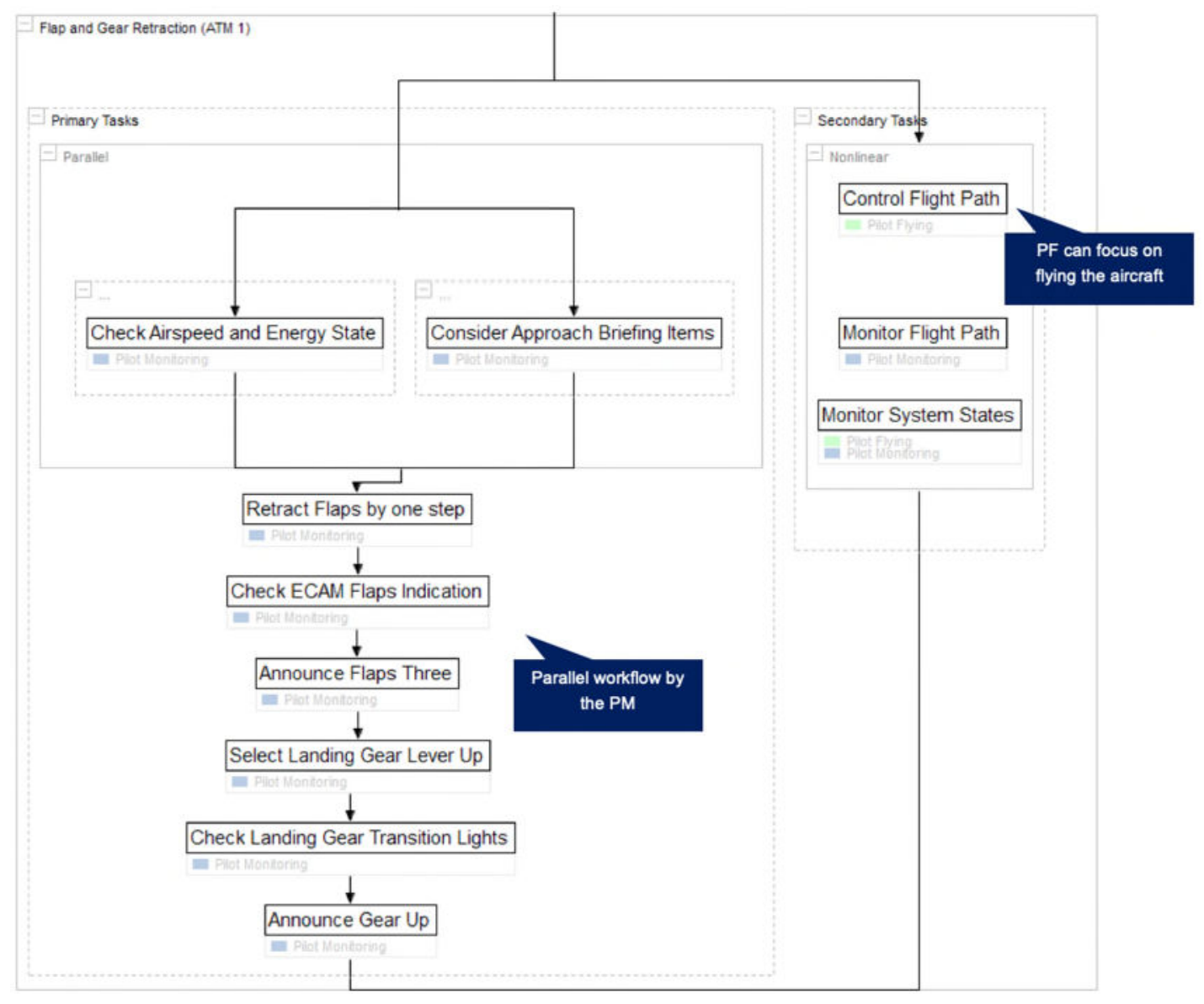

Figure 2. Parallel workflow of the PM during flap and gear retraction of the modified procedure.

Figure 2 shows that the process gate to perform the flap and gear retraction is opened and closed by the PM without prior command. This is the key feature of introducing parallel workflows: The PF can focus on flying the aircraft while the PM performs tasks independently. The design modification affects the flap and gear retraction at GA initiation, configuration management after passing the minimum flap retraction speed for configuration $1+\mathrm{F}$ (Flap Retraction Phase above F-Speed) as well as the slat retraction when accelerating above the minimum slat retraction speed (Slat Retraction Phase above S-Speed). 

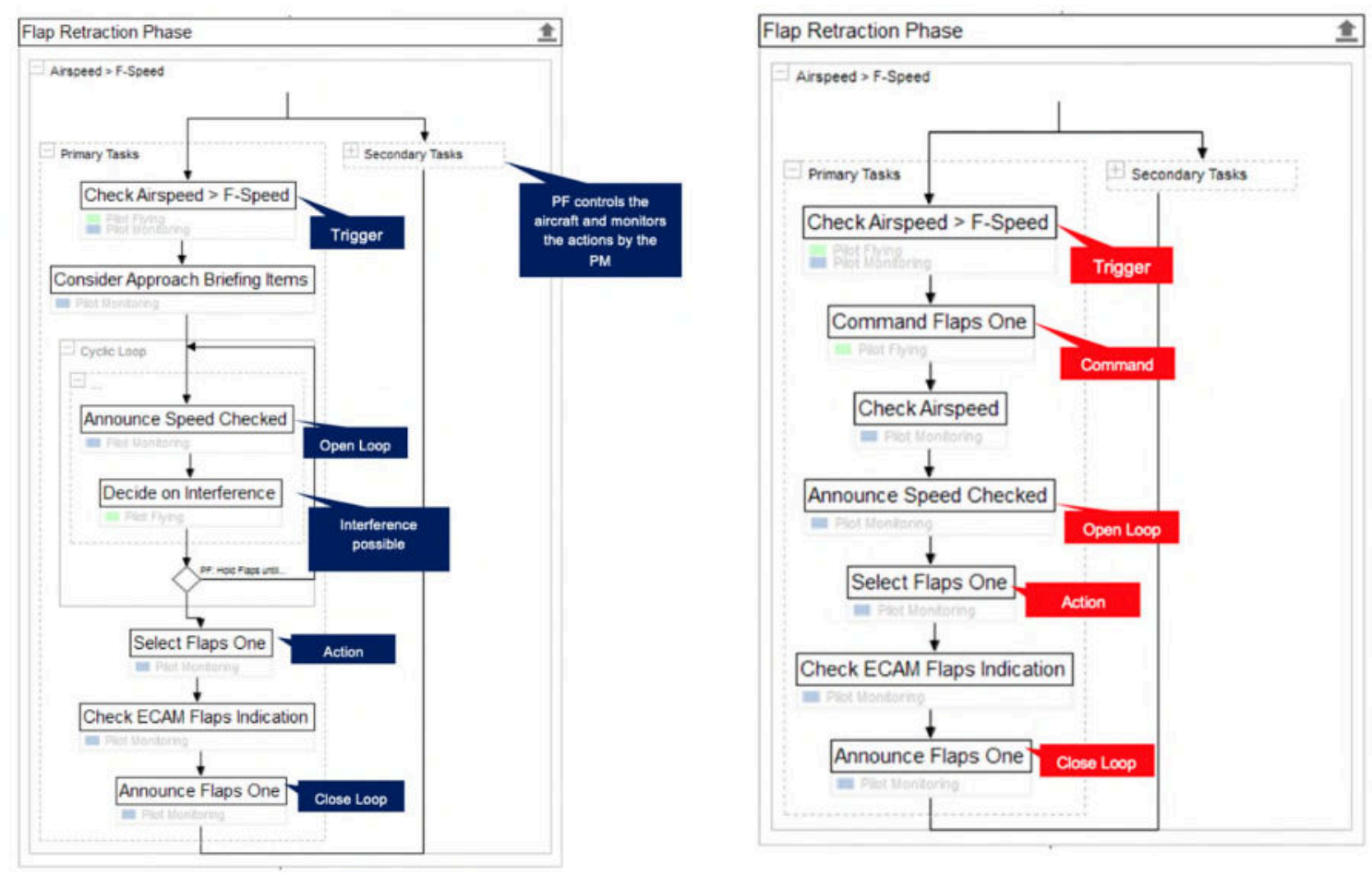

Figure 3. Manufacturer (left) versus modified (right) A320 GA SOP showing the flap retraction after passing the minimum flap retraction speed for configuration $1+F(F-S p e e d)$.

Figure 3 shows an example when reaching the minimum flap retraction speed for configuration $1+\mathrm{F}$. The PM triggers and executes the action based on a comparison between the indicated airspeed and the F-Speed bug (Speed > F-Speed) on the PFD. The PM controls the timing of the flap retraction without waiting for a command by the PF that may delay the procedure sequence. This improves the smoothness of the workflow. However, mutual monitoring by the PF remains necessary. Thus, the PM informs the PF about the beginning of the action block by the callout "Speed Checked". Thereby, the PF can still monitor the PM's action and may decide to interfere by announcing "Hold Flaps" or by informing the PM before reaching the scheduled flap retraction speed. Also, the PF may use the approach briefing to inform the PM well in advance about the intended flap setting. The possibility to interfere is still mandatory since the configuration change influences the energy management of the aircraft which remains a primary function allocated to the PF (Cahill et al., 2014). In closing, the configuration is still a shared duty, but while being in a dynamic and complex phase of flight, it is triggered and executed by the PM in a parallel workflow. 


\section{Supporting adaptive task management}

The ATM concept enhances the flexibility of the procedure in so-called disturbed GAs (BEA, 2013) that require immediate changes to the flight guidance modes. Examples are complex controller transmissions shortly before initiating the GA through assigning a different heading, lower level off altitude, airspeed or rate of climb. Flight crew cannot use the preprogrammed missed approach of the Flight Management System (FMS) and this may increase workload (BEA, 2013). Manual inputs must be made to the Flight Control Unit (FCU). These changes affect the flight director bars which assist the PF to maintain a specified flightpath.

The ATM concept introduces two functional action blocks to help in the management of these dynamic changes. ATM1 combines both the flap and gear retraction. ATM2 includes all required manipulations of the vertical and lateral flight guidance modes at the FCU to comply with the air traffic control clearance, ensuring that the flight director bars used by the PF are accurate. Activities within the ATM are mainly performed by the PM. Figure 4 shows the normal sequence during the GA when applying the modified procedure (Option 1). The callout "Positive Climb" triggers the ATM with the standard sequence ATM 1 before ATM2, i.e. the PM retracts the flaps and landing gear before changing the flight guidance modes. Therefore, the procedure sequence follows the manufacturer philosophy giving priority to aviate over navigate which represents the most probable GA scenario when following the published missed approach (Granger \& Jeanpierre, 2011). The navigational task is less critical because the aircraft automatically re-engages the lateral flight guidance mode NAV after setting the Take-off/Go-Around Thrust (Owens, 2011). ATM2 only requires a crosscheck of the FMA which is triggered by the PF via callout followed by a non-verbal check by the PM. 


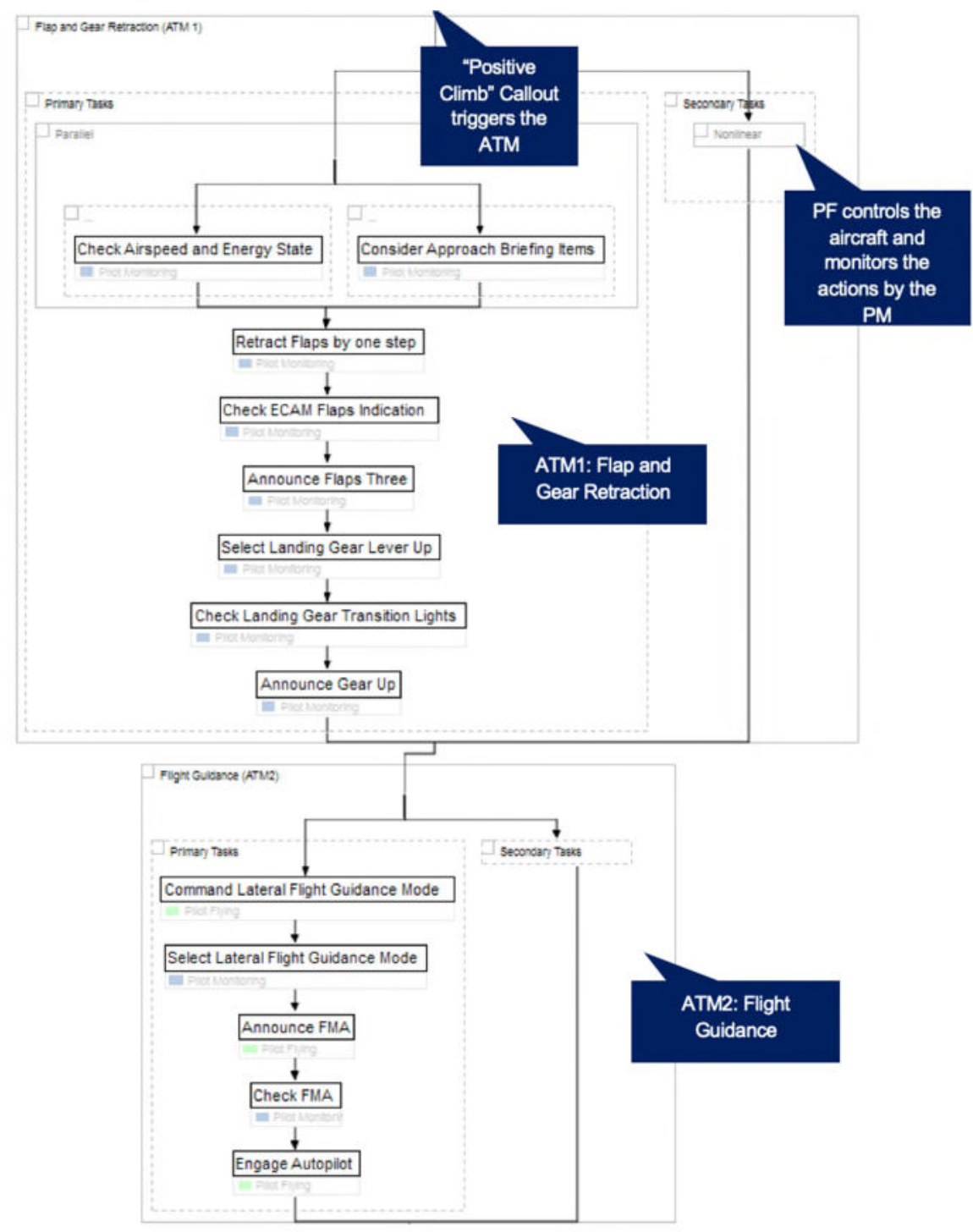

Figure 4. Adaptive Task Management (Option 1) - ATM1 followed by ATM2.

In the event of an unexpected change of the published missed approach, the PM can set own priorities in task execution by performing ATM2 before ATM1. The ability to modify the task sequence addresses the fact that the operational and environmental context at GA initiation has an impact on the optimum timing of procedural steps (Cahill et al., 2014). Again, we take advantage of the AOTW by completing ATM2 before reaching the maximum flaps extended speed (VFE) for Flaps Full. In this case, we exhausted the AOTW leaving no margin left between performing ATM2 and ATM1. Therefore, the flight crews are expected to perform heading and altitude changes followed by a flap and gear retraction without delay. However, once an ATM is initiated, the PM shall complete the tasks without mixing it with the 
next ATM. Since there is no margin left, we acknowledge that an impending overspeed situation of the flaps is an exception to this rule. With Flaps Full the VFE of the aircraft is exceeded before reaching the structural limitation of the main landing gear. To avoid damage to the flaps, the PM can initiate ATM2 and retracts the flaps when approaching VFE. The PF might inform the PM about the impending overspeed situation with the standard callout "Speed".

\section{References}

BEA, Bureau d'Enquêtes et d'Analyses 2013. Study on Aeroplane State Awareness during Go-Around. Le Bourget, France.

Cahill, J., McDonald, N. and Losa, G. 2014. A Sociotechnical Model of the Flight Crew Task, Human Factors 56(8): 1337-1363. Available at: https://doi.org/10.1177/ 0018720814532684.

Degani, A. and Wiener, E. L. 1994. On the Design of Flight-Deck Procedures. Moffett Field, California: NASA Ames Research Center.

Granger, S. and Jeanpierre, E. 2011. Automatic NAV engagement at Go Around. Safety First - The Airbus Safety Magazine (11): 19-21.

Kourdali, H. K. \& Sherry, L. 2017. Available Operational Time Window (AOTW): A Method for Evaluating Airline Standard Operating Procedures. Journal of Cognitive Engineering and Decision Making 11(4): 371-381. Available at: https://doi.org/10.1177/1555343417727190.

Owens, D. 2011. The Go-Around Procedure. Safety First - The Airbus Safety Magazine (12): 10-22. 


\section{Evaluating process-based and crew-} centred approaches to procedure design in aviation: workload and performance changes in go-around manoeuvres

\section{Schmidt, Tim André}

Elsevier

Schmidt TA, Kourdali HK, Nixon J. (2021) Evaluating process-based and crew- centred approaches to procedure design in aviation: workload and performance changes in go-around manoeuvres. Applied Ergonomics, Volume 90, January 2021, Article number 103244

https://doi.org/10.1016/j.apergo.2020.103244

Downloaded from Cranfield Library Services E-Repository 